\title{
Proteinase-antiproteinase balance in tracheal aspirates from neonates
}

\author{
K.B. Sluis*, B.A. Darlow**, M.C.M. Vissers*, C.C. Winterbourn*
}

Proteinase-antiproteinase balance in tracheal aspirates from neonates. K.B. Sluis, B.A. Darlow, M.C.M. Vissers, C.C. Winterbourn. OERS Journals Ltd 1994.

ABSTRACT: We wanted to identify the inhibitors of neutrophil elastase, quantify their activities in the upper airways of neonates, and relate these to the presence of active elastase and the likelihood of elastolytic injury occurring due to inhibitory capacity being overwhelmed.

Activities of neutrophil elastase and its inhibitors were measured in tracheal aspirates from 17 infants, 10 of whom subsequently developed bronchopulmonary dysplasia.

All aspirates contained immunologically detectable $\alpha_{1}$-proteinase inhibitor $\left(\alpha_{1}\right.$-PI), but their inhibitory capacity against neutrophil elastase ranged from being undetectable to being in excess of the amount of $\alpha_{1}$-PI detected immunologically. When the $\alpha_{1}$ PI was removed from each of the aspirates, using a specific antibody, from 0-50\% of the original activity remained, indicating the presence of another elastase inhibitor. Its properties were consistent with it being the low molecular mass, secretory leucoproteinase inhibitor (SLPI), also known as bronchial antileucoproteinase. The $\alpha_{1}$-PI was from 0-100\% active. Most of the inactive inhibitor was shown by western blotting to be complexed with elastase, with a small amount of cleaved material. There was no evidence of major oxidative inactivation. Free elastase was detected in only three of the aspirates; these had little or no detectable elastase inhibitory capacity, and most of their $\alpha_{1}$-PI was complexed. Elastase load, comprising the sum of free and complexed elastase, correlated closely with myeloperoxidase activity, a recognized marker of inflammatory activity. Active SLPI levels showed a positive correlation with gestational age $(\mathbf{r}=\mathbf{0 . 6 6})$.

We conclude that most neutrophil elastase in the upper airways of ventilated infants is complexed. This indicates that lung secretions of most infants contain adequate inhibitory activity of $\alpha_{1}$-PI and probably secretory leucoproteinase inhibitor. Eur Respir J., 1994, 7, 251-259.
Dept of *Pathology and **Paediatrics, Christchurch School of Medicine, Christchurch, New Zealand.

Correspondence: C.C. Winterbourn Dept of Pathology

Christchurch School of Medicine

P O Box 4345

Christchurch

New Zealand

Keywords: $\alpha_{1}$-proteinase inhibitor bronchial antileucoproteinase bronchopulmonary dysplasia neonatal respiratory distress neutrophil elastase

secretory leucoproteinase inhibitor

Received: March 161993

Accepted after revision August 171993

This work was supported by grants from the Health Research Council of New Zealand and the Foundation for the Newborn.
Premature infants that require ventilation frequently develop bronchopulmonary dysplasia (BPD) and other forms of chronic lung disease [1]. The pathogenesis of the disease $[2,3]$ is thought to include injury mediated by neutrophils, which are prevalent in lung aspirates from neonates with respiratory distress $[4,5]$. They release reactive oxidants and proteinases, including elastase, which degrades elastin and other connective tissue proteins. Excessive proteolytic activity has been implicated in the development of BPD [3,6].

Protection against proteolytic injury is provided by the elastase inhibitor, $\alpha_{1}$-proteinase inhibitor $\left(\alpha_{1}-\mathrm{PI}\right)$ or $\alpha_{1}$ antitrypsin, which is present in lung lining fluid [7]. A low molecular mass elastase inhibitor, secretory leucocyte proteinase inhibitor (SLPI), also known as bronchial antileucoproteinase and mucus proteinase inhibitor, has also been characterized [8, 9]. In the adult, SLPI is synthesized primarily by serous cells of the bronchial glands, and by Clara and goblet cells in the peripheral airways [10]. It is considered to act mainly but not exclusively, in the upper airways, where it may provide more protection than $\alpha_{1}$-PI $[7,9]$. SLPI has been detected in foetal lung cells during development $[11,12]$. Proteolytic injury to the lungs can occur if inhibitory capacity is overwhelmed, either through formation of complexes with elastase, cleavage by non-target proteinases, or oxidative inactivation.

Several studies have measured elastase activity in tracheal aspirates from intubated neonates [4-6, 13-16]. When related to total $\alpha_{1}$-PI levels, elastase activity remained high in infants who developed BPD [4,5], it was increased in association with prolonged hyperoxia or infection [6], but there was no sustained elevation in infants treated with surfactant. Most of the studies, however, did not simultaneously measure elastase inhibitory capacity, and the one that did, surprisingly, found the coexistence of active elastase and active $\alpha_{1}$-PI [4]. Published evidence suggests that some of the $\alpha_{1}$-PI in infant tracheal aspirates is complexed or oxidatively inactivated $[4,17]$. However, no quantitative assessment has been carried out of the relationship between elastase activity and the form of its 
inhibitors; and the role of SLPI has not been assessed. Furthermore, there have been no measurements of inhibitory capacity against neutrophil elastase, which is the major target for $\alpha_{1}-\mathrm{PI}$, rather than pancreatic elastase, which exhibits different specificity. This information is needed to assess the importance of proteinase/inhibitor balance as a factor in the development of BPD.

The objective of our study was to obtain profiles of elastase and its inhibitors in tracheal aspirates from premature infants with respiratory distress and requiring ventilation. Measurements have been made of immunological levels of $\alpha_{1}$-PI and the proportions of complexed and cleaved forms. Inhibitory capacities against neutrophil elastase, with and without removing the $\alpha_{1}$-PI by immunoprecipitation, and free elastase activities have been measured. Studies have also been performed with porcine pancreatic elastase and trypsin, both for comparison with earlier work, and to assess oxidative inactivation of the $\alpha_{1}$-PI.

\section{Materials and methods}

\section{Study group}

Christchurch Women's Hospital is the regional neonatal unit for an area with some 7,000 births per annum. Infants admitted to the neonatal unit who required intubation and ventilation (approximately 90 annually) were candidates for the study, provided that the parents or guardian had given informed written consent. The study was approved by the Canterbury Area Health Board Ethics Committee.

Tracheal aspirates were collected from 17 infants born in 1991, details of whom are given in table 1. Ten infants ultimately developed BPD. They were smaller (mean birthweight $1,165 \mathrm{~g}$ ) and had shorter gestation (mean 28 weeks) than those who did not develop BPD (mean birthweight 2,683 $\mathrm{g}$ and gestation 35 weeks). Four infants were treated with one or more doses of intravenous indomethacin, and none were treated with steroids prior to endotracheal sampling.

\section{Collection and preparation of tracheal aspirates}

Collection of tracheal aspirate samples followed a standard protocol, with frequency of suctioning being the minimum necessary to maintain patency of the airway. Initial suction was without instillation of saline, the catheter being passed in a measured way to $0.5 \mathrm{~cm}$ below the tube tip, and suction applied as the catheter was withdrawn. If secretions were present and not cleared by dry suction, $0.5-1 \mathrm{ml}$ of isotonic saline was instilled, followed by five ventilator breaths, and the tube aspirated as before. Only the initial aspirates were analysed. The catheters containing the aspirated secretions were stored at $4^{\circ} \mathrm{C}$ for no longer than $12 \mathrm{~h}$ before processing. This compares with similar studies that have stored aspirates for up to $24 \mathrm{~h}$ [6]. Storage changes could confound our results, primarily through the activation or lysis of neutrophils and release of elastase. To check for this, levels of another neutrophil constituent, myeloperoxidase, were monitored for four aspirates from each of two individuals, obtained on the same day and stored for varying times up to $16 \mathrm{~h}$. Myeloperoxidase activities $\cdot \mathrm{g}^{-1}$ albumin varied by $<20 \%$ for each individual, and showed no sign of increasing with time. Additionally, for the aspirates used in the study, there was no correlation between either myeloperoxidase activity or elastase load

Table 1. - Profiles of the infants in the study group

\begin{tabular}{|c|c|c|c|c|c|c|c|c|}
\hline Infant & $\begin{array}{c}\text { Birth } \\
\text { weight } \\
\mathrm{g}\end{array}$ & $\begin{array}{l}\text { Gestation } \\
\text { week }\end{array}$ & $\begin{array}{l}\text { Sex } \\
M / F\end{array}$ & Surfactant $\dagger$ & $\begin{array}{l}\text { Time on } \mathrm{O}_{2} \\
\text { days }\end{array}$ & $\begin{array}{l}\text { Age at sample } \\
\text { days }\end{array}$ & Primary diagnosis & $\begin{array}{l}\text { Development } \\
\text { of } \mathrm{BPD}^{\$}\end{array}$ \\
\hline$a^{*}$ & 1990 & 34 & $\mathrm{~F}$ & + & 7 & 2 & RDS & - \\
\hline $\mathrm{b}$ & 3990 & 40 & $\mathrm{~F}$ & - & 8 & 6 & Birth asphyxia & - \\
\hline $\mathrm{c}$ & 3410 & 40 & M & - & 13 & 5 & Birth asphyxia & - \\
\hline $\mathrm{d}$ & 2130 & 33 & M & + & 9 & 5 & RDS & - \\
\hline $\mathrm{e}$ & 3900 & 40 & $\mathrm{~F}$ & - & 21 & 18 & Meconium aspiration & - \\
\hline $\mathrm{f}$ & 2200 & 30 & M & + & 12 & 36 & RDS & - \\
\hline $\mathrm{g}$ & 1160 & 28 & $\mathrm{~F}$ & - & 5 & 2 & RDS & - \\
\hline $\mathrm{h}$ & 995 & 27 & $\mathrm{~F}$ & + & 76 & 7 & RDS & + \\
\hline $\mathrm{i}$ & 750 & 27 & $\mathrm{~F}$ & + & 81 & 6 & RDS & + \\
\hline $\mathrm{j}$ & 880 & 26 & $\mathrm{~F}$ & + & 33 & 8 & RDS & + \\
\hline $\mathrm{k}$ & 1310 & 28 & $\mathrm{~F}$ & + & 58 & 2 & RDS & + \\
\hline 1 & 870 & 26 & M & + & 53 & 5 & RDS & + \\
\hline $\mathrm{m}$ & 1080 & 26 & M & + & 51 & 5 & RDS & + \\
\hline $\mathrm{n}$ & 2150 & 34 & $\mathrm{~F}$ & - & 54 & 12 & Congenital pneumonia & + \\
\hline o & 1080 & 28 & M & + & 104 & 6 & $\mathrm{RDS}$ & + \\
\hline $\mathrm{p}$ & 1030 & 28 & M & - & 37 & 12 & RDS & + \\
\hline$q$ & 1500 & 31 & $\mathrm{~F}$ & + & 41 & 2 & RDS & + \\
\hline
\end{tabular}

*: the arabic letter code is consistent throughout the tables and figures. $\uparrow$ : Exosurf (Wellcome, NZ) administered as one or more rescue doses prior to sample collection. \$: defined as an early requirement for ventilation, clinical respiratory distress and oxygen dependence for more than 28 days, and a characteristic chest radiograph [1]. F: female; M: male; RDS: respiratory distress syndrome; BDP: bronchopulmonary dysplasia. 
(defined below) and storage time $(\mathrm{r}=-0.35$ and -0.19 , respectively). Therefore, artefacts due to storage are unlikely.

Samples from the same individual within that $12 \mathrm{~h}$ period were pooled. A minimal volume $(0.5-1.5 \mathrm{ml})$ of phosphate buffered saline (10 mM sodium phosphate buffer $\mathrm{pH} 7.4$, $140 \mathrm{mM}$ sodium chloride, $2.7 \mathrm{mM}$ potassium chloride) was repeatedly drawn through the tube to loosen secretions. The same solution was used for all tubes collected from each individual over the $12 \mathrm{~h}$ period. The washings were then filtered through glass wool and spun at $12,000 \times \mathrm{g}$ for $5 \mathrm{~min}$ to pellet cells and cellular debris. Supernatants were removed and stored at $-80^{\circ} \mathrm{C}$.

\section{Materials}

Polyclonal rabbit antisera against human serum albumin, human $\alpha_{1}$-PI and human lactoferrin were obtained from Dako A/S (Denmark). Polyclonal SLPI antiserum was a gift from S. Smith (Charing Cross and Westminster Medical School, London). Supported nitrocellulose $(0.2 \mu \mathrm{m})$ was from Schleicher and Schuell (Dassel, Germany). Purified human serum albumin was from Behring (Marburg, France). $\alpha_{1}$-PI was purified from human plasma by thiol disulphide interchange [18]. Titration against active site titrated trypsin [19] showed it to be $80 \%$ active. Polyacrylamide gel electrophoresis in the presence of sodium deodecyl sulphate (SDS-PAGE) showed a single band at $52 \mathrm{kDa}$. Human neutrophil elastase was purified by trasylol affinity and ion exchange chromatography [20]. It was shown to be free of cathepsin $\mathrm{G}$ activity and migrated at $30 \mathrm{kDa}$ on SDS-PAGE. All other reagents were from Sigma Chemical Co., St Louis, Mo, USA, unless otherwise stated.

\section{Measurement of total $\alpha_{1}$-PI and albumin}

Albumin and $\alpha_{1}$-PI were measured by immunoelectrophoresis [21], using purified human serum albumin or $\alpha_{1^{-}}$ PI as standards. The detection limit was $0.02 \mathrm{~g} \cdot l^{-1}$ for albumin and $1.0 \mathrm{mg} \cdot l^{-1}$ for $\alpha_{1}$-PI. The coefficient of variation was $<5 \%$ for both assays.

\section{Proportion of $\alpha_{1}$-PI complexed with neutrophil elastase}

This was measured in tracheal aspirates by enhanced chemiluminescent western blotting, using a kit obtained from Amersham International Plc, (Amersham UK). Samples were subjected to SDS-PAGE on $10.5 \%$ gels, followed by transfer of the proteins to $0.2 \mu \mathrm{m}$ supported nitrocellulose. All blocking, incubation and washing steps were carried out in $50 \mathrm{mM}$ Tris buffer $\mathrm{pH} 7.9$, containing $150 \mathrm{mM}$ sodium chloride, $0.05 \%$ Tween 20 and $3 \%$ nonfat dried milk powder. The first incubation was with antihuman $\alpha_{1}$-PI antiserum, followed by incubation with mouse anti-rabbit IgG antiserum coupled to horseradish peroxidase. The membrane was exposed to the chemiluminescent reagents, and to X-ray film (X-Omat AR, Kodak). The relative amounts of the different $\alpha_{1}$-PI components were determined from the developed film, using densitometry. Developmental work by the manufacturers has demonstrated a linear relationship between density and protein concentration.

\section{Inhibitory capacity of tracheal aspirates}

Inhibitory capacities against neutrophil elastase, trypsin and porcine pancreatic elastase were measured by a variation of the method described by BEATTY et al. [22]. Samples were added to either $15 \mathrm{nM}$ elastase, $20 \mathrm{nM}$ trypsin, or $20 \mathrm{nM}$ pancreatic elastase, in $50 \mathrm{mM}$ Tris buffer $\mathrm{pH} 7.5$ with $200 \mathrm{mM} \mathrm{NaCl}, 1 \mathrm{~g} \cdot l^{-1}$ bovine serum albumin and $0.05 \%$ Tween 20 . All reactions were carried out at $37^{\circ} \mathrm{C}$ in microtitre plates (final volume $200 \mu \mathrm{l}$ ). After 5 min preincubation at $37^{\circ} \mathrm{C}$, residual proteinase activity was assayed, using the specific substrates $\mathrm{N}$-methoxysuccinylala-ala-pro-val $p$-nitroanilide for neutrophil elastase, $\alpha \mathrm{N}$ benzoyl- $d l$-arg $p$-nitroanilide for trypsin, or N-succinyl-alaala-ala $p$-nitroanilide for pancreatic elastase, at final concentrations of $8 \times 10^{-4} \mathrm{M}$. The assay was monitored at 0 and 90 min at $405 \mathrm{~nm}$, using an enzyme-linked immunosorbent assay (ELISA) plate reader (Titertek Multiscan), and the percentage inhibition of each proteinase was calculated. Results are expressed as active $\alpha_{1}$-PI equivalents, determined from a standard curve constructed using purified $\alpha_{1}$-PI.

\section{Removal of $\alpha_{1}$-PI by immunoprecipitation and ultrafiltration}

To $25 \mu$ of tracheal aspirate sample (maximum amount of $\alpha_{1}$-PI $1.45 \mathrm{mg}$ ) were added $12.5 \mu$ of rabbit anti-human $\alpha_{1}$-PI antiserum (or anti-lactoferrin as control), $4 \mathrm{mg}$ of preswelled protein A-sepharose, and $87.5 \mu \mathrm{l}$ of $40 \mathrm{mM}$ sodium phosphate buffer pH 7.2, containing $300 \mathrm{mM}$ sodium chloride and $1 \mathrm{~g} \cdot l^{-1}$ bovine serum albumin. The samples were gently rotated at $4^{\circ} \mathrm{C}$ for $2 \mathrm{~h}$. Sepharosebound immunoprecipitates were spun down. The supernatants were analysed for immunological $\alpha_{1}$-PI and albumin, and inhibitory capacity against neutrophil elastase, trypsin and pancreatic elastase.

Removal of proteins with a molecular mass of $>30 \mathrm{kDa}$ (including $\alpha_{1}-\mathrm{PI}$ ) was performed on two samples, using small volume molecular mass cut-off filters (micron microconcentrators, Amicon). Ultrafiltrates were analysed for immunological $\alpha_{1}$-PI and inhibitory capacity against neutrophil elastase.

\section{Activity of free neutrophil elastase}

Neutrophil elastase activity was measured using the synthetic chromogenic substrate N-methoxysuccinyl-alaala-pro-val $p$-nitroanilide [22]. Aspirate samples (20 $\mu \mathrm{l})$ were diluted to a final volume of $200 \mu \mathrm{l}$ in the Tris buffer used for measuring inhibitory capacity. The reaction was initiated by adding $8.5 \times 10^{-4} \mathrm{M}$ substrate in $10 \mu \mathrm{l}$ dimethylsulphoxide. The microtitre plates were incubated at $37^{\circ} \mathrm{C}$ and monitored at $405 \mathrm{~nm}$ at zero time, and then at 60 and $120 \mathrm{~min}$, to measure high and low activity, respectively. A standard curve was constructed using 1-75 nM neutrophil elastase, the activity of which was calibrated against active $\alpha_{1}$-PI. 


\section{Myeloperoxidase activity}

Myeloperoxidase was assayed using the tetramethylbenzidine method [23].

\section{Statistical analysis}

Statistical comparisons between groups of infants were tested using Student's t-test. If necessary, data were transformed to obtain equal variances. Linear regression was used to compute the coefficients of determination $\left(\mathrm{r}^{2}\right)$, from which the correlation coefficients ( $r$ ) were determined.

\section{Results}

All measurements were related to the amount of albumin present, to account for the variable dilution with buffered saline that necessarily occurs during sample collection. Although there are reservations about albumin as a reference [16], this is also true of the alternative urea dilution method, and an ideal reference has yet to be devised. Albumin has been employed in other studies [4-6, 12]. Proteinase and inhibitor concentrations have been standardized relative to $\alpha_{1}$-PI and are expressed as $\mathrm{nM} \alpha_{1}$-PI equivalents. Since the inhibitors form 1:1 mole complexes with elastase, this enables quantitative assessment of proteinase/inhibitor profiles to be made.

\section{Concentration and form of $\alpha_{1}$-PI in tracheal aspirates}

Aspirates from all the infants studied contained immunologically detectable $\alpha_{1}$-PI, (table 2). Where sufficient sample was available, the form of the $\alpha_{1}$-PI was investigated by electrophoresis and western blotting. Bands with molecular masses of 52, 46 and $82 \mathrm{kDa}$ were detected (fig. 1), corresponding, respectively, to native $\alpha_{1}-\mathrm{PI}$, cleaved $\alpha_{1^{-}}$ PI and $\alpha_{1}$-PI complexed to neutrophil elastase [24]. Samples ranged from having almost all the $\alpha_{1}$-PI with its native molecular weight (six individuals), to nearly all in a complexed form (three individuals). Cleaved $\alpha_{1}$-PI was seen only when complex was present, and there was always more complexed than cleaved material. The percentages of the different components are shown beneath figure 1.

Cleavage could have occurred by a nonsubstrate proteinase, e.g. collagenase, by elastase acting on oxidized $\alpha_{1}-\mathrm{PI}$, or by degradation of complex. The latter explanation is most likely, since prolonged storage and handling of aspirates led to an increase in the proportion of cleaved $\alpha_{1}$-PI with a corresponding decrease in complex, but no change in the level of native protein (results not shown).

\section{Elastase inhibitory capacity}

Total inhibitory capacity of the tracheal aspirates against purified human neutrophil elastase varied from being undetectable to being in excess of the amount of $\alpha_{1}$-PI that was detected immunologically (table 2). This indicates that an inhibitor other than $\alpha_{1}$-PI may have been present in some aspirates, and also that the $\alpha_{1}$-PI in many of the aspirates was not fully active. Some showed no activity. These had the highest amount of complex (fig. 1). Activities against trypsin and porcine pancreatic elastase were also

Table 2. $-\alpha_{1}-$ PI levels and inhibitory capacities of individual tracheal aspirates

\begin{tabular}{lcccc}
\hline & \multicolumn{4}{c}{ Inhibitory capacity against } \\
\cline { 2 - 5 } Infant & $\begin{array}{c}\text { Immunological } \\
\alpha_{1} \text {-PI }\end{array}$ & $\begin{array}{c}\text { Neutrophil } \\
\text { elastase }\end{array}$ & Trypsin & $\begin{array}{c}\text { Pancreatic } \\
\text { elastase }\end{array}$ \\
\hline $\mathrm{a}$ & 1170 & $\mathrm{ND}$ & $\mathrm{ND}$ & $\mathrm{ND}$ \\
$\mathrm{b}$ & 1540 & 2180 & 890 & 950 \\
$\mathrm{c}$ & 1230 & 2640 & 400 & 830 \\
$\mathrm{~d}$ & 960 & 890 & 520 & 520 \\
$\mathrm{e}$ & 560 & 340 & 120 & 200 \\
$\mathrm{f}$ & 590 & 800 & 260 & 560 \\
$\mathrm{~g}$ & 1010 & 150 & 30 & 170 \\
$\mathrm{~h}$ & 790 & 700 & 400 & 520 \\
$\mathrm{i}$ & 1290 & 770 & 640 & 640 \\
$\mathrm{j}$ & 790 & 0 & 0 & 180 \\
$\mathrm{k}$ & 1400 & 720 & 580 & 640 \\
$\mathrm{l}$ & 1130 & 730 & 680 & 650 \\
$\mathrm{~m}$ & 900 & 640 & 390 & 510 \\
$\mathrm{n}$ & 940 & 270 & 90 & 280 \\
$\mathrm{o}$ & 640 & 190 & 120 & 200 \\
$\mathrm{p}$ & 1600 & 0 & 0 & 0 \\
$\mathrm{q}$ & 890 & 840 & 580 & 670 \\
\hline Mean(sD) & $1030(320)$ & $740(720)$ & $360(280)$ & $470(270)$ \\
\hline
\end{tabular}

Inhibitory capacities against neutrophil elastase, trypsin and pancreatic elastase were determined using chromogenic substrates as described in the Methods sections. All values are expressed as nmol $\alpha_{1}$-PI (or $\alpha_{1}$-PI equivalents).g-1 albumin. $\alpha_{1}$-PI: alpha ${ }_{1}$ proteinase inhibitor. ND: not determined. 


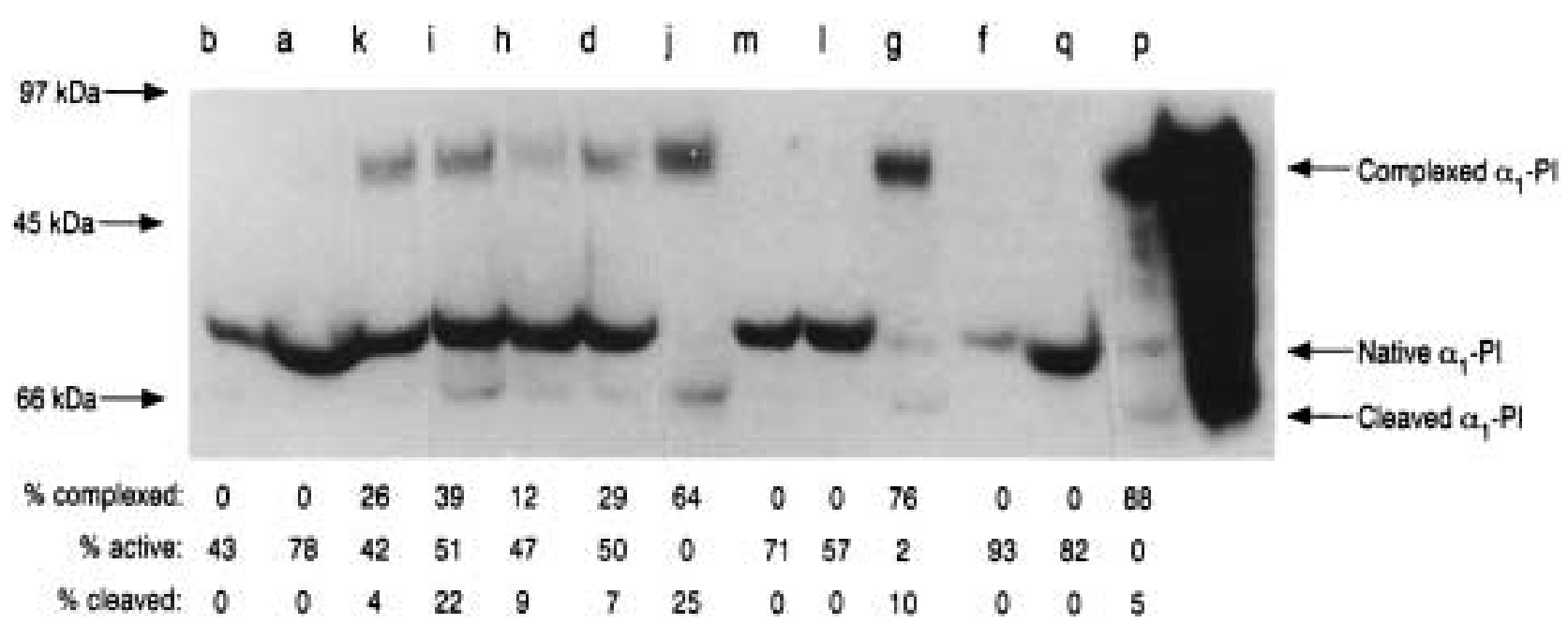

Fig. 1. - Western blots of the tracheal aspirates separated by SDS-PAGE and reacted with polyclonal antiserum against $\alpha_{1}$-PI. Bands were visualized by enhanced chemiluminescence. The percentages of complexed and cleaved $\alpha_{1}$-PI were determined by densitometry, the percentages of active $\alpha_{1}$-PI were calculated from the data in figure 2. The arrows on the left correspond to the positions of molecular weight markers. The

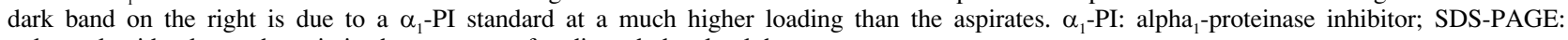
polyacrylamide electrophoresis in the presence of sodium dodecyl sulphate.

measured. Mean activities against both were significantly lower than against neutrophil elastase (table 2).

When all the $\alpha_{1}$-PI was removed from the aspirates by immunoprecipitation, on average $42 \pm 32 \%$ of the neutrophil elastase inhibitory capacity remained. This indicated the presence of another elastase inhibitor. The inhibitory capacity due to $\alpha_{1}$-PI was calculated for each aspirate as the difference in activity before and after immunoprecipitation. This value was in each case less than the amount of immunologically detectable $\alpha_{1}$-PI (fig. 2). From $0-93 \%$ of the $\alpha_{1}$-PI was active, with a mean value for all the aspirates of $47 \%$. When the percentages of active $\alpha_{1}$-PI are added to cleaved and complexed material (fig. 1) almost all the $\alpha_{1}$-PI can be accounted for.

Removal of the $\alpha_{1}$-PI from the aspirates decreased inhibitory capacity against trypsin by $81 \pm 31 \%$, and against pancreatic elastase by $73 \pm 21 \%$. The remaining inhibitory capacity, therefore, was substantially less against both these enzymes than against neutrophil elastase. It also follows that most of the inhibitory capacity of the aspirates against trypsin and pancreatic elastase was due to $\alpha_{1}$-PI. By comparing these activities, it is possible to assess whether the $\alpha_{1}$-PI was oxidatively inactivated. Native $\alpha_{1}$-PI is equally active against both enzymes, while active site oxidized

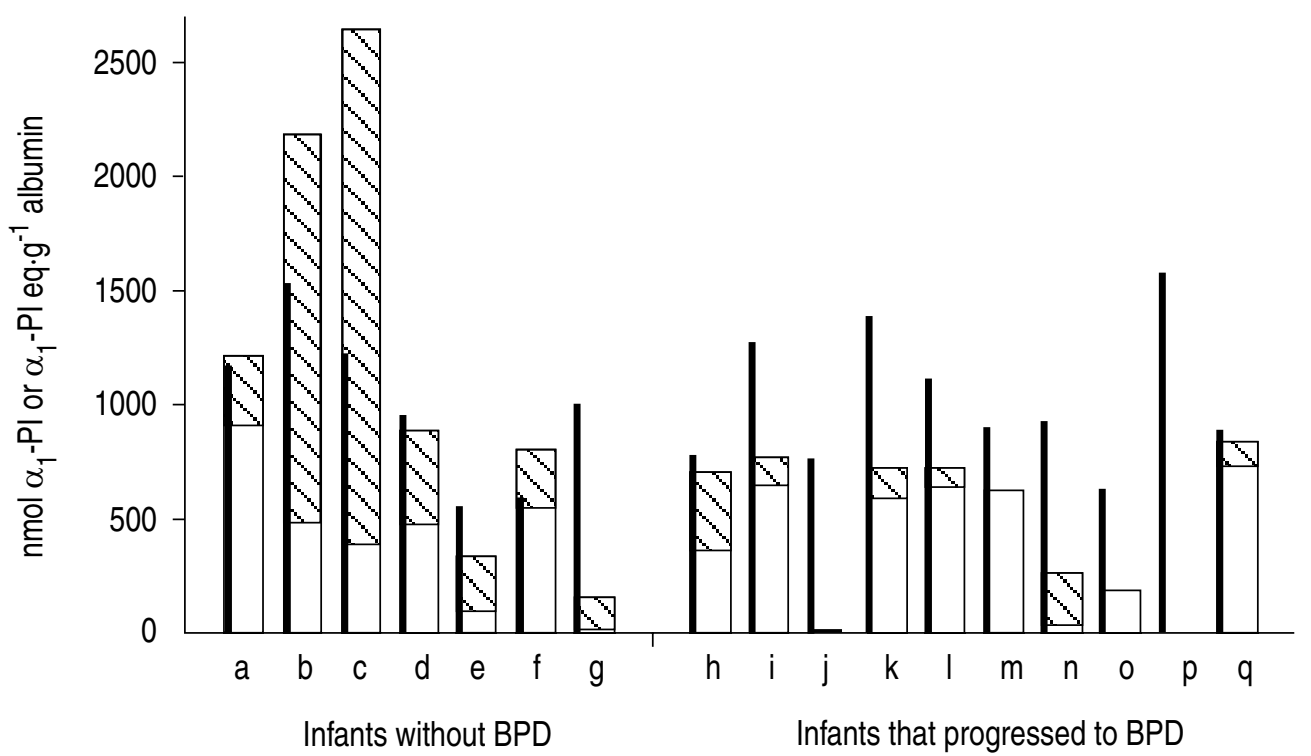

Fig. 2. - Contribution of $\alpha_{1}$-PI to the inhibitory capacities of the individual tracheal aspirates against neutrophil elastase. Immunological levels of $\alpha_{1}$-PI are from table 1. Aspirates were treated with antisera against $\alpha_{1}$-PI and against lactoferrin as control, as described in the Methods section. Measurements were made of the inhibitory capacity remaining after treatment with the control antibody (total inhibitory capacity) and the inhibitory capacity remaining after treatment with anti- $\alpha_{1}$-PI. The difference is the activity due to $\alpha_{1}$-PI. Treatment of the aspirates with the control antibody altered the levels of elastase inhibition capacity by $<5 \%$. After treatment with anti- $\alpha_{1}$-PI, no immunological $\alpha_{1}$-PI was detected, whereas

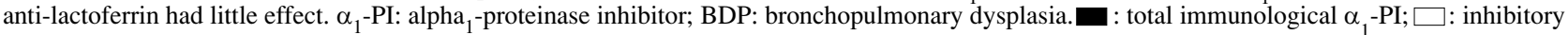
capacity due to $\alpha_{1}$-PI; $\square+\square$ : total inhibitory capacity. 
$\alpha_{1}$-PI is active against trypsin and completely inactive against pancreatic elastase [22]. Oxidation, therefore, results in relatively higher activity against trypsin. On average, there was in fact slightly lower activity against trypsin than pancreatic elastase (table 2 ), with no individual showing evidence of substantial oxidative inactivation. The calculated inhibitory capacities against trypsin and pancreatic elastase due solely to $\alpha_{1}$-PI (mean ratio $0.77 \pm 0.37$ ) lead to a similar conclusion. This is supported by the data in figure 1 , showing that most of the $\alpha_{1}$-PI is already accounted for as active, complexed or cleaved forms.

The inhibitory capacity not due to $\alpha_{1}$-PI was further characterized by passing the two aspirates with the highest activity through a membrane with a $30 \mathrm{kDa}$ molecular mass cut-off that excluded $\alpha_{1}$-PI. In each case, about $50 \%$ of the activity against neutrophil elastase passed through the membrane. Hence, the inhibitor had a molecular mass of $<30 \mathrm{kDa}$. To test whether it could be SLPI $(12 \mathrm{kDa}$ molecular mass), western blots of several aspirates were carried out. Antiserum against SLPI recognized a band of about $17 \mathrm{kDa}$, which was present only in samples exhibiting significant elastase inhibitory capacity that was not due to $\alpha_{1}$-PI. As other bands of higher molecular mass were also recognized by the antibody, the results are supportive of the inhibitor being SLPI, but do not provide unequivocal identification. With this reservation, we have used the term SLPI in subsequent discussion.

\section{Neutrophil elastase activity}

Active neutrophil elastase was detected in only 3 of the 13 aspirates examined (table 3). These three aspirates showed no or minimal elastase inhibitory capacity (table

Table 3. - Elastase and myeloperoxidase levels in individual tracheal aspirates

\begin{tabular}{lcccr}
\hline Infant & $\begin{array}{c}\text { Complex } \\
\text { with } \alpha_{1} \text {-PI }\end{array}$ & $\begin{array}{c}\text { Free } \\
\text { elastase }\end{array}$ & $\begin{array}{c}\text { Elastase } \\
\text { load }\end{array}$ & MPO \\
\hline a & 0 & 0 & 0 & 26 \\
$\mathrm{~b}$ & 0 & 0 & 0 & ND \\
$\mathrm{d}$ & 278 & 0 & 278 & 51 \\
$\mathrm{e}$ & $\mathrm{ND}$ & $\mathrm{ND}$ & $\mathrm{ND}$ & 25 \\
$\mathrm{f}$ & 0 & 0 & 0 & 10 \\
$\mathrm{~g}$ & 765 & 6 & 771 & 256 \\
$\mathrm{~h}$ & 95 & 0 & 95 & 29 \\
$\mathrm{i}$ & 503 & 0 & 503 & 90 \\
$\mathrm{j}$ & 506 & 30 & 536 & 131 \\
$\mathrm{k}$ & 364 & 0 & 364 & 42 \\
$\mathrm{l}$ & 0 & 0 & 0 & 22 \\
$\mathrm{~m}$ & 0 & 0 & 0 & 30 \\
$\mathrm{n}$ & $\mathrm{ND}$ & $\mathrm{ND}$ & $\mathrm{ND}$ & 122 \\
$\mathrm{o}$ & $\mathrm{ND}$ & $\mathrm{ND}$ & $\mathrm{ND}$ & 101 \\
$\mathrm{p}$ & 1408 & 221 & 1629 & 313 \\
$\mathrm{q}$ & 0 & 0 & 0 & 5 \\
\hline
\end{tabular}

Free elastase was determined using chromogenic substrates as described in the Methods section. Elastase load is the sum of free elastase and that complexed with $\alpha_{1}$-PI, calculated from the total amount of $\alpha_{1}$-PI determined immunologically and the proportion of complex determined by densitometry (fig. 1). Values are expressed as nmol elastase. $\mathrm{g}^{-1}$ albumin. Myeloperoxidase activities were related to the purified enzyme and are expressed as nmol.g ${ }^{-1}$ albumin. ND: not determined; $\alpha_{1}$-PI: alpha 1 -proteinase inhibitor; MPO: myeloperoxidase.

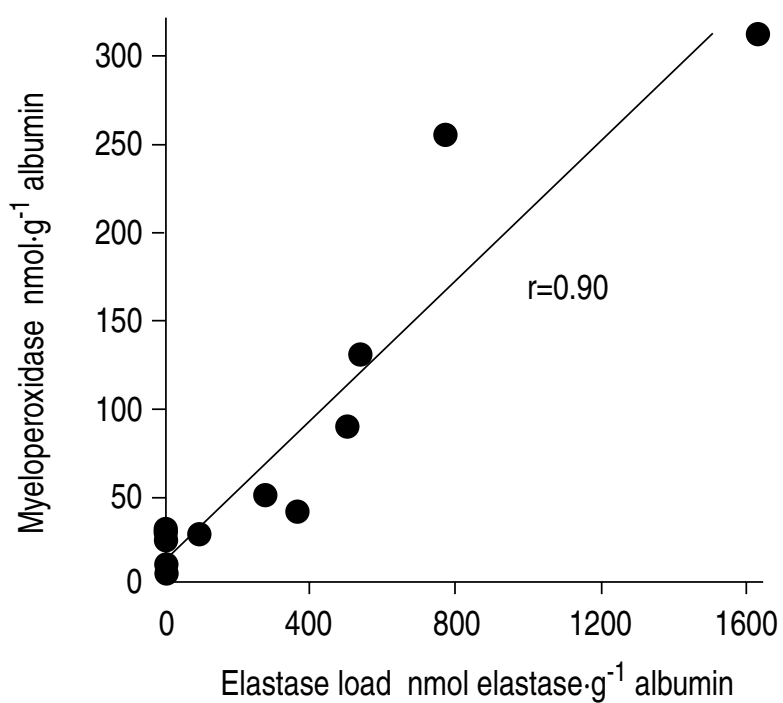

Fig. 3. - Relationship between myeloperoxidase activity and elastase load in tracheal aspirates. Data are from table 3.

2), and their $\alpha_{1}$-PI was almost exclusively complexed (fig. 1). The chromogenic assay used measures both free elastase and elastase bound to $\alpha_{2}$-macroglobulin [25]. When the assay was repeated in the presence of $\alpha_{1}$-PI to measure only the enzyme bound to $\alpha_{2}$-macroglobulin, no activity was detected.

\section{Elastase load and relationship to myeloperoxidase activity}

The sum of the active elastase plus that complexed to $\alpha_{1}$-PI, defined as the elastase load (table 3 ), should reflect the total amount of elastase released from neutrophils in the lungs. Myeloperoxidase is present in the same neutrophil granules as elastase, so the two should be released together if the cells are activated. There was a close correlation between myeloperoxidase activity and elastase load in the aspirates (table 3 and fig. 3). This correlation substantiates the relationship between each activity and neutrophil activation. It also implies that elastase load is a valid measure of all the elastase released into the lungs, and suggests that there is little degradation to products not detected in our assays.

\section{Relationships to age}

Data were analysed for relationships with postconceptional age and age after birth. For total $\alpha_{1}$-PI, $\alpha_{1}$-PI inhibitory capacity against neutrophil elastase, elastase load and myeloperoxidase activity, all expressed. $\mathrm{g}^{-1}$ albumin, there was no correlation with either parameter $(\mathrm{r}<0.25)$. A positive correlation was found between gestational age and active SLPI ( $\mathrm{r}=0.66$, fig. $4 \mathrm{a})$, and to a lesser extent, total elastase inhibitory capacity ( $\mathrm{r}=0.54$; results not shown). Neither correlated with age after birth $(\mathrm{r}=0.10$, fig $4 \mathrm{~b}$ and $r=0.14$ for total inhibitory capacity; results not shown). The total inhibitory capacity is the sum of the activities of $\alpha_{1-}$ PI, which did not correlate with post conceptional age $(r=0.14)$, and SLPI. Therefore, the correlation with total inhibitory capacity is due to the contribution of the SLPI. 

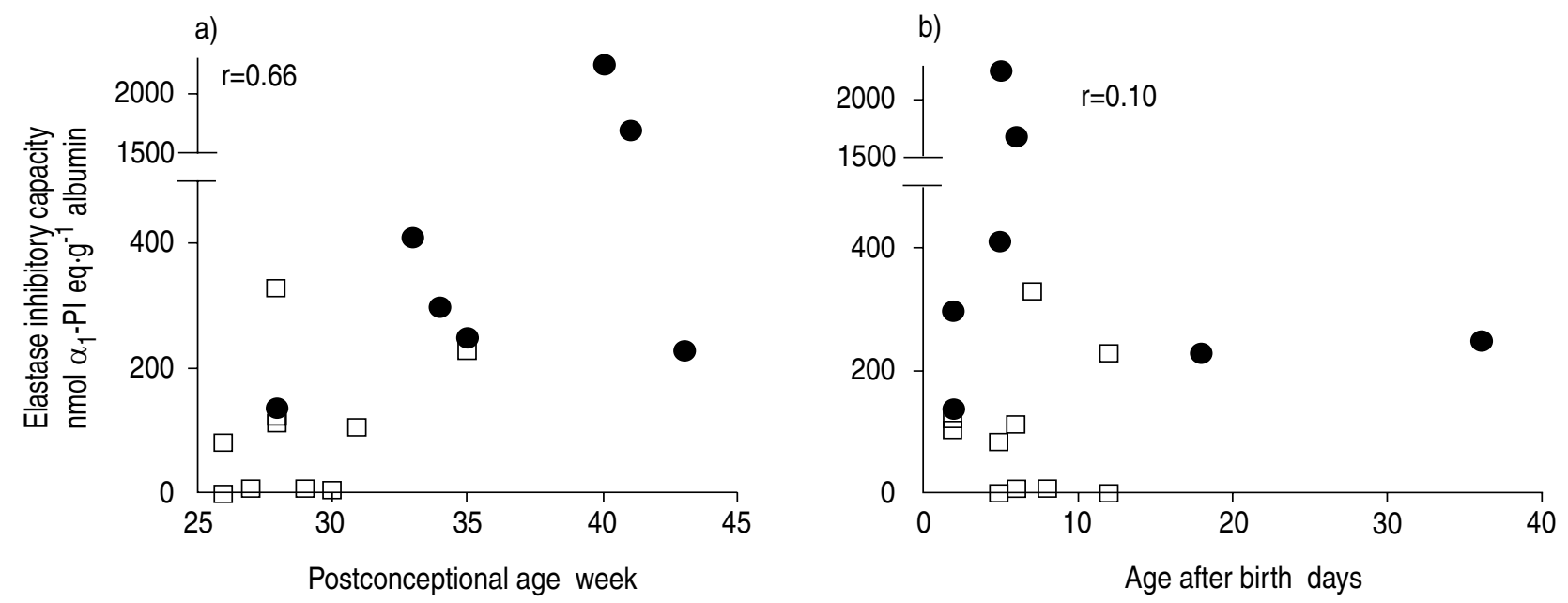

Fig. 4. - Relationship between elastase inhibitory capacity attributed to SLPI and (a) postconceptional age and (b) age after birth. Inhibitory capacity data are from figure 2. : infants that did not develop BPD; $\square$ : infants that progressed to develop BPD. SLPI: secretory leucoproteinase inhibitor; BPD: bronchopulmonary dysplasia.

\section{Relationships to development of bronchopulmonary dysplasia}

The infants that developed BPD had lower mean birth weight and gestational age than those that did not, so the data cannot be used to establish causal relationships with BPD. Nevertheless, it is noteworthy that, with the exception of SLPI activity, there were no significant differences between the infants that developed BPD and those without lung disease (table 4). Although SLPI levels were significantly different, this could simply reflect the well-established association between gestational age and development of BPD.

Although no significant difference was seen for elastase load or myeloperoxidase, a difference is suggested if num- bers of samples with appreciable enzyme activity are compared (table 2). For elastase load, 5 out of 8 BPD infants had detectable amounts, compared with 2 out of 5 infants that did not develop BPD. Similarly for myeloperoxidase, 6 out of 10 BPD infants were above the median level compared with 2 out of 5 non-BPD infants.

\section{Discussion}

Using immunoassays and activity measurements standardized with purified $\alpha_{1}$-PI or human neutrophil elastase of known activity, we have obtained quantitative profiles of elastase and its inhibitors in tracheal aspirates from

Table 4. - Mean values for infants that did and did not progress to develop BPD

\begin{tabular}{|c|c|c|c|}
\hline & No BPD & BPD & $\mathrm{p}$ \\
\hline $\begin{array}{l}\text { Total } \alpha_{1}-\mathrm{PI} \\
\mathrm{nmol} \cdot \mathrm{g}^{-1} \text { albumin }\end{array}$ & $\begin{array}{l}1008 \pm 350 \\
\quad(\mathrm{n}=7)\end{array}$ & $\begin{array}{c}1037 \pm 307 \\
(\mathrm{n}=10)\end{array}$ & 0.860 \\
\hline $\begin{array}{l}\text { Total elastase inhibitory capacity } \\
\text { nmol } \alpha_{1} \text {-PI eq. } \mathrm{g}^{-1} \text { albumin }\end{array}$ & $\begin{array}{l}1167 \pm 1012 \\
\quad(\mathrm{n}=6)\end{array}$ & $\begin{array}{c}486 \pm 333 \\
(\mathrm{n}=10)\end{array}$ & 0.090 \\
\hline $\begin{array}{l}\alpha_{1} \text {-PI elastase inhibitory capacity } \\
\text { nmol } \alpha_{1} \text {-PI eq.g-1 albumin }\end{array}$ & $\begin{array}{l}329 \pm 220 \\
(\mathrm{n}=6)\end{array}$ & $\begin{array}{c}429 \pm 288 \\
(\mathrm{n}=9)\end{array}$ & 0.480 \\
\hline $\begin{array}{l}\text { SLPI elastase inhibitory capacity } \\
\text { nmol } \alpha_{1}-\text { PI eq.g-1 albumin }\end{array}$ & $\begin{array}{c}753 \pm 853 \\
(n=7)\end{array}$ & $\begin{array}{c}100 \pm 109 \\
(n=10)\end{array}$ & 0.009 \\
\hline $\begin{array}{l}\text { Elastase load } \\
\text { nmol elastase } \cdot \mathrm{g}^{-1} \text { albumin }\end{array}$ & $\begin{array}{c}209 \pm 335 \\
(\mathrm{n}=5)\end{array}$ & $\begin{array}{c}380 \pm 525 \\
(\mathrm{n}=8)\end{array}$ & 0.530 \\
\hline $\begin{array}{l}\text { Myeloperoxidase } \\
\mathrm{nmol} \cdot \mathrm{g}^{-1} \text { albumin }\end{array}$ & $\begin{array}{l}73.6 \pm 103 \\
(\mathrm{n}=5)\end{array}$ & $\begin{array}{c}88.5 \pm 90.7 \\
(\mathrm{n}=10)\end{array}$ & 0.780 \\
\hline $\begin{array}{l}\text { Post conceptional age } \\
\text { weeks }\end{array}$ & $\begin{array}{c}36.3 \pm 5.3 \\
(\mathrm{n}=7)\end{array}$ & $\begin{array}{l}28.8 \pm 2.7 \\
(\mathrm{n}=10)\end{array}$ & 0.002 \\
\hline Age at sample days & $\begin{array}{l}10.6 \pm 12.5 \\
(\mathrm{n}=7)\end{array}$ & $\begin{array}{c}6.5 \pm 3.5 \\
(\mathrm{n}=10)\end{array}$ & 0.340 \\
\hline
\end{tabular}

Data are presented as mean \pm SD with numbers of infants in parenthesis. Comparisons between the groups were made using paired t-test. For abbreviations see legends to tables 1 and 2 . 
17 infants with respiratory distress. $\alpha_{1}$-PI was detected immunologically at concentrations that did not vary greatly in relation to albumin. It ranged, however, from being fully active to fully inactive, and in some cases did not account for all the inhibitory capacity. Most of the inactive $\alpha_{1}$-PI was accounted for quantitatively by complexes with elastase, plus a small amount of cleaved material which probably arose from breakdown of the complexes. We saw no evidence of oxidative inactivation, although with the limitations of the assay, small changes of perhaps $20 \%$ would not be detected. However, the close agreement between the amounts of complex plus cleaved material determined by immunoblotting and the amount of inactive inhibitor from activity assays implies that oxidation is not a major mechanism of inactivation. This is somewhat surprising, given the oxidative environment of the ventilated lung and the large amounts of reactive oxygen species released by stimulated neutrophils, but may represent the level of antioxidant protection present.

About half of the aspirates contained detectable elastase. Most was complexed to $\alpha_{1}$-PI, and in only three aspirates was elastase activity detected. These aspirates had no inhibitory capacity, and their $\alpha_{1}$-PI was almost entirely complexed. This is consistent with the theory that there should be no elastase activity in the presence of active inhibitor. This was also the case in a recent study of neonates with respiratory distress [16], and in bronchitis and emphysema patients [26]. The sum of free and complexed elastase, or elastase load [26], should represent all the elastase released from neutrophils, and be a measure of inflammatory activity in the lungs. The close correlation found between it and myeloperoxidase, which is considered to be a good inflammatory marker [27], is confirmation of this. Previous studies $[4,5]$ have concluded that development of BPD is associated with higher neutrophil activity. Our results are consistent with this.

Not all the elastase inhibitory capacity of the aspirates was due to $\alpha_{1}$-PI. A low molecular mass inhibitor, behaving like the $12 \mathrm{kDa}$ elastase inhibitor SLPI $[8,9,28]$, was detected. SLPI is active against neutrophil elastase and trypsin but not porcine pancreatic elastase [28, 29]. Our activity measurements suggest less reactivity against trypsin and pancreatic elastase than against neutrophil elastase. Aspirates containing the inhibitor responded positively to antiserum raised against SLPI, but not as a single $12 \mathrm{kDa}$ band. However, other investigators have reported higher molecular mass immunoreactive bands [30].

A recent study has reported the presence of SLPI in infant lung secretions [12], but no activity measurements were made. SLPI has also been detected immunologically in autopsy samples from foetal lungs [11]. It was found in submucosal glands and the epithelium of the trachea by 20 weeks gestation, but not in the bronchiolar epithelium until 36 weeks. Our finding of a strong correlation between the amount of active SLPI and gestational age suggests that significant amounts of active SLPI are not released until near the end of gestation, and that very premature infants are born with very low levels. Longitudinal studies are needed to substantiate this.

Further controlled studies are needed to establish whether low SLPI activity in premature neonates constitutes a risk factor for the development of BPD. This is an important question with practical implications, as recombinant SLPI is available with the potential for therapeutic use [31, 32].

We conclude that ventilated infants show variable degrees of inflammatory activity, associated with release of neutrophil elastase and myeloperoxidase. Most of the elastase is complexed, and only in a minority of infants is free elastase detectable. This implies that, on a global level, the lung secretions of most infants contain adequate inhibitory activity, in the form of $\alpha_{1}$-PI and probably SLPI. However, as with all studies of this type [7], analysis of total lung aspirate would not necessarily show localized areas of proteolytic imbalance. Therefore, increased elastase load without free elastase in the total aspirate; especially in association with low SLPI levels, could represent local imbalance sufficient to cause proteolytic injury.

Our findings differ from other studies with neonates, that detected free elastase in most or all of the aspirates examined [4-6, 13-16]. The explanation may lie in the assays used. OGDen et al. [5] and BRUCE et al. [6] both used an assay that measures degradation of labelled elastin and runs for up to $18 \mathrm{~h}$, whereas ours is a short chromogenic assay using a specific substrate for neutrophil elastase. The elastin assay is not necessarily specific for neutrophil elastase, and more importantly it can measure elastase complexed to SLPI, which dissociates during the long assay period [33]. Much of the elastase measured in those studies, therefore, may have been bound to SLPI. While SLPI is not particularly effective at inhibiting in vitro elastin degradation, GAUTHIER et al. [9] have concluded that the complexes are sufficiently stable for it to be an effective elastase inhibitor in vivo.

Another difference is that we measured activities against neutrophil elastase with a substrate designed for the neutrophil enzyme, whereas others [4-6,13-15] have used pancreatic elastase or its substrate. Pancreatic elastase differs substantially in its reactivity, and does not give absolute activities or inhibitory capacities for the neutrophil enzyme [22]. We detected inhibitory activity in excess of $\alpha_{1}$-PI only with neutrophil elastase. This is consistent with SLPI being less reactive with the pancreatic enzyme [29].

Our results suggest that oxidative inactivation of $\alpha_{1}$-PI in infants with respiratory distress is not a major effect. However, some oxidation is implied by the finding of an increase in inhibitory capacity of lung $\alpha_{1}$-PI after incubation with dithiothreitol [17]. The other study to address this question was that of MERRITT et al. [4], who proposed that the cleaved material present in $\alpha_{1}$-PI isolated from infant lung fluid arose from degradation of oxidized protein. However, our finding of gradual conversion of elastase complexes to cleaved $\alpha_{1}$-PI in stored samples suggests that their result could be due to breakdown of complexes during purification. The extent to which oxidative inactivation of $\alpha_{1}$-PI occurs in adult respiratory disease is still a contentious issue [7]. Accurate assessment of whether oxidation of $\alpha_{1}$-PI or SLPI occurs in neonates awaits more sensitive and direct analysis.

Acknowledgements: The assistance of the nursing staff of the Neonatal Unit, Christchurch Women's Hospital, in the collection of aspirates is gratefully acknowledged. 


\section{References}

1. Bancalari E, Gerhardt T. Bronchopulmonary dysplasia. Ped Clin N Am 1986; 33: 1-23.

2. Farrell PM, Zimmerman JJ. Bronchopulmonary dysplasia. Curr Opin Pediatr 1992; 4: 410-416.

3. Merritt TA, Hallman M. Interactions in the immature lung: protease-antiprotease mechanism of lung injury. In: Contemporary Issues in Fetal and Neonatal Medicine. 4. Bronchopulmonary Dysplasia. Boston, Blackwell Scientific, 1988; pp. 117-130.

4. Merritt TA, Cochrane CG, Holcomb K, et al. Elastase and $\alpha_{1}$-proteinase inhibitor activity in tracheal aspirates during respiratory distress syndrome. J Clin Invest 1983; 72: 656-666.

5. Ogden BE, Murphy SA, Saunders GC, Pathak D, Johnson JD. Neonatal lung neutrophils and elastase/proteinase inhibitor imbalance. Am Rev Respir Dis 1984; 130: 817-821.

6. Bruce MC, Schyler M, Martin RJ, Starcher BC, Tomashefski JF, Wedig KE. Risk factors for the degradation of lung elastic fibers in the ventilated neonate. Am Rev Respir Dis 1992; 146: 204-212.

7. Stockley RA, Morrison HM. Elastase inhibitors of the respiratory tract. Eur Respir J 1990; 3 (Suppl. 9): 9s$15 \mathrm{~s}$.

8. Stockley RA, Morrison HM, Smith S, Tetley T. Low molecular mass bronchial proteinase inhibitor and $\alpha_{1}$-proteinase inhibitor in sputum and bronchoalveolar lavage. Hoppe-Seyler's Z Physiol Chem 1984; 365: 587595.

9. Gauthier F, Fryksmark U, Ohlsson K, Bieth JG. Kinetics of the inhibition of leukocyte elastase by the bronchial inhibitor. Biochim Biophys Acta 1982; 700: 178-183.

10. De Water R, Willems LWA, van Muijen GNP, et al. Ultrastructural localization of bronchial antileukoprotease in central and peripheral human airways by a gold-labeling technique using monoclonal antibodies. Am Rev Respir Dis 1986; 133: 882-890.

11. Willems LNA, Kramps JA, Jeffery PK, Dijkman JH. Antileukoprotease in the developing fetal lung. Thorax 1988; 43: 784-786.

12. Ohlsson K, Sveger T, Svenningsen N. Protease inhibitors in bronchoalveolar lavage fluid from neonates with special reference to secretory leukoprotease inhibitor. Acta Paediatr 1992; 81: 757-759.

13. Walti H, Tordet C, Gerbaut L, Saugier P, Moriette G, Relier JP. Persistent elastase/proteinase inhibitor imbalance during prolonged ventilation of infants with bronchopulmonary dysplasia: evidence for the role of nosocomial infections. Pediatr Res 1989; 26: 351-355.

14. Gerdes JS, Harris MC, Polin RA. Effects of dexamethasone and indomethacin on elastase, $\alpha_{1}$-proteinase inhibitor and fibronectin in bronchoalveolar lavage fluid from neonates. J Pediatr 1988; 113: 727-731.

15. Gerdes J, Whitsett J, Long W. Elastase activity and surfactant protein concentration in tracheal aspirates from neonates receiving synthetic surfactant. J Pediatr 1992; 120: S34-S39.

16. Speer CP, Ruess D, Harms K, Herting E, Gefeller O. Neutrophil elastase and acute pulmonary damage in neonates with severe respiratory distress syndrome. Pediatrics 1993; 91: 794-799.

17. Bruce M, Boat T, Martin R, Dearborn D, Fanaroff A. Proteinase inhibitors and inhibitor inactivation in neonatal airways secretions. Chest 1982; 81(5): 44S-45S.

18. Laurell C-B, Piece J, Persson U, Thulin E. Purification of $\alpha_{1}$-antitrypsin from plasma through thiol disulphide interchange. Eur J Biochem 1975; 57: 107-113.

19. Chase T, Shaw E. Titration of trypsin, plasmin and thrombin with $p$-guanadine benzoate-HCl. Methods Enzymol 1970; 19: 20-27

20. Barrett A. Cathepsin G and leukocyte elastase. Methods Enzymol 1981; 80: 561-588.

21. Laurell C-B. Electroimmunoassay. Scand J Clin Lab Invest 1972; 29 (suppl. 124): 21-23.

22. Beatty K, Bieth J, Travis J. Kinetics of association of serine proteinases with native and oxidised $\alpha_{1}$-proteinase inhibitor and $\alpha_{1}$-antichymotrypsin. J Biol Chem 1980; 255: 3931-3934.

23. Suzuki K, Ota H, Sasagawa S, Sakatini T, Fujikura T. Assay method for myeloperoxidase in polymorphonuclear leukocytes. Anal Biochem 1983; 132: 345.

24. Stockley RA, Afford SC. Qualitative studies of lung lavage $\alpha_{1}$-proteinase inhibitor. Hoppe-Seyler's Z Physiol Chem 1984; 365: 503-510.

25. Twumasi DY, Liener IE. Activation of human leukocyte elastase by human $\alpha_{2}$-macrogolobulin. Nature 1977; 10/267: 61-63.

26. Fujita J, Nelson NL, Daughton DM, et al. Evaluation of elastase and antielastase balance in patients with chronic bronchitis and pulmonary emphysema. Am Rev Respir Dis 1990; 142: 57-62.

27. Schmekel B, Karlsson SE, Linden M, Sundstrom C, Tegner H, Venge P. Myeloperoxidase in human lung lavage. 1. A marker of local neutrophil activity. Inflammation 1990; 14: 447-454.

28. Thompson RC, Ohlsson K. Isolation, properties and complete amino acid sequence of human secretory leukocyte protease inhibitor, a potent inhibitor of leukocyte elastase. Proc Natl Acad Sci 1986; 83: 6692-6696.

29. Schiessler H, Arnold M, Ohlsson K, Fritz H. Inhibitors of acrosin and granulocyte proteinases from human genital tract secretions. Z Phys Chem 1976; 357(9): 1251-1260.

30. Van-Seuningen I, Davril M, Haymen A. Evidence for the tight binding of human mucus proteinase inhibitor to highly glycosylated macromolecules in sputum. Biol Chem Hoppe-Seyler 1989; 370: 749-755.

31. Lucey EC, Stone PJ, Ciccolella DE, et al. Recombinant human secretory leukocyte-protease inhibitor: in vitro properties, and amelioration of human neutrophil elastaseinduced emphysema and secretory cell metaplasia in the hamster. J Lab Clin Med 1990; 115: 224-232.

32. Rudolphus A, Kramps JA, Dijkman JH. Effect of human antileucoprotease on experimental emphysema. Eur Respir J 1991; 4: 31-39.

33. Kramps JA, Morrison HM, Burnett D, Dijkman JH, Stockley RA. Determination of elastase inhibitory activity of $\alpha_{1}$-proteinase inhibitor and bronchial antileukoproteinase: different results using insoluble elastin or synthetic low molecular weight substrates. Scand J Clin Lab Invest 1987; 47: 405-410. 